\title{
Information Management for Manufacturing SMEs
}

\author{
Thorsten Wuest and Klaus-Dieter Thoben \\ Bremer Institut für Produktion und Logistik GmbH (BIBA), \\ Hochschulring 20,28359 Bremen, Germany \\ \{wue, tho\}@biba.uni-bremen. de
}

\begin{abstract}
Manufacturing SMEs are the backbone of the prosperous German engineering sector. Known for advanced technology and premium quality, they face a constant need to improve their processes. This is especially true for SMEs involved in collaborative production networks. Within these networks, each partner is required to constantly improve their process and product quality. One possible method to accomplish this, is by improving the information management based on the product state. An elementary requirement for such a system is to understand the SME specific challenges. This paper will provide an overview of special conditions of manufacturing SMEs, derive requirements on product state based information management and provide insights and recommendations of implementing such a system by using practical examples.
\end{abstract}

Keywords: information management, SME, manufacturing, product state, collaboration, in-process, quality.

\section{Introduction}

The prosperous German economy, seen as an engine of growth within the European Union [1], depends heavily on the strong industrial sector, in particular, the division of mechanical engineering due to its reputation for advanced technology and premium quality $[2,3]$. The backbone of this German engineering success are at large the specialized manufacturing Small and Medium Sized Enterprises (SMEs). However, being successful does not necessarily mean that there is no potential for further improvements [4]. On the contrary, as manufacturing SMEs develop over time, they face new challenges brought forth by global competition, which focuses heavily on quality and price. Partly, the manufacturing processes of certain SMEs are not competitive compared to Multinational Enterprises (MNEs) which actively manage their value adding processes [4]. Manufacturing processes are constantly becoming more complex and are increasingly carried out at multiple locations [5]. This developments add to the need to strategically engage in process improvement in order to stay competitive on a global scale. As SMEs are part of collaborative production networks that are actively involved in complex product creation with other companies of different size and organization (e.g. MNEs, SMEs), they have to fulfill certain requirements on both process and product quality or even have use certain technologies for the sake and as a basis of collaborative success (see Fig.1) $[6,7]$. Therefore, end product quality does 
not only depend on internal quality of each stakeholder but also on interdependencies amongst these stakeholders. A vivid understanding of these interdependencies can be seen as a basic requirement for improving quality in collaborative networks [8].

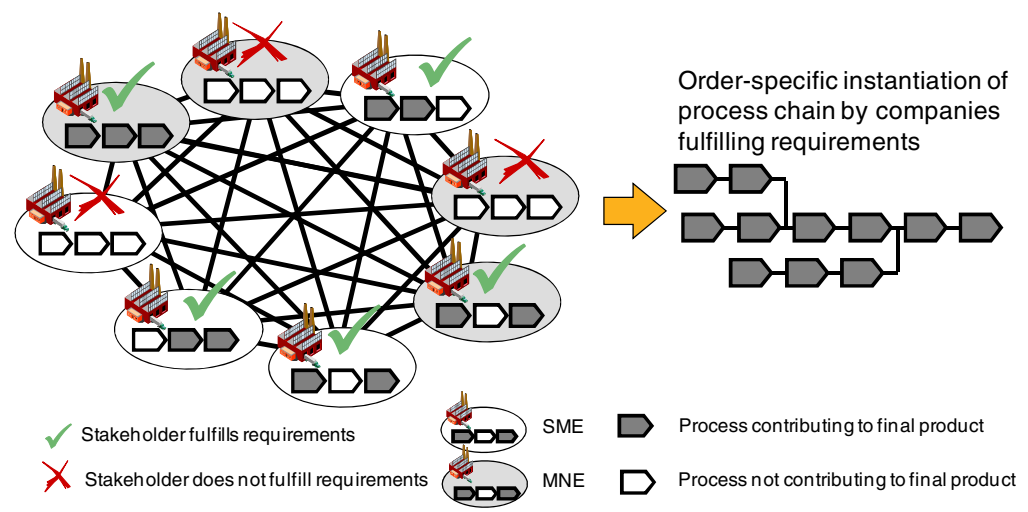

Fig. 1. Necessity for stakeholders to fulfill requirements (e.g. on quality like ISO 9001) in order to participate in collaborative production (compare [5])

Manufacturing SMEs today, even with their highly specialized operations and complex products, often have out-dated solutions for their information management. Another frequently found options is that the companies have up-to-date information management systems but either no trained or responsible personnel or no transparency over the own manufacturing processes and information/data needs.

One important aspect within this area is the ability to continuously derive detailed information of a product throughout the whole manufacturing process, e.g. supported by tracking and tracing. This creates the basis for practical information management systems as well as quality improvement and assurance [9]. On the one side, such a system helps to improve internal quality of stakeholders and thus provides the basis for enhanced quality of the whole network and the final product. On the other side, it provides customers with a continuous proof of the product state [10] along the manufacturing process. In some high-tech industries such as the aerospace industry, there are already specifications in place which enforce a continuous tracing of products and permanent access to connected information throughout the whole supply chain [11]. All companies trying to conduct business within this industry need to prove their capability to comply with these requirements. Other industries, like the food or pharmaceutical industry have to follow rigid legislations as well [12].

In the following section, general characteristics of manufacturing SMEs will be presented incl. two practical example of manufacturing SMEs mainly active in the automotive sector, one producing gear wheels and the other impellers. Section three will shortly introduce information management in the manufacturing industry. Whereas section four will derive requirements and recommendations for manufacturing SMEs which are planning to implement information management. Section five will conclude the paper and will also provide an outlook for further areas of research. 


\section{Characteristics of Manufacturing SMEs}

SMEs represent the majority of companies in Germany and are crucial for the economy $[4,7]$. In this section, major characteristics of manufacturing SMEs in Germany with information management will be presented (see table 1).

As the name already implies, SMEs are smaller, both in sales volume and number of employees (less than 250 employees according to EU definition [13]) than for example MNEs. Thereby, the organizational structure of SMEs is less complex and informal [14]. This allows SMEs to be more flexible and react quickly to changing market conditions. They also have strong ties to their customers and have to fulfill the quality requirements that are demanded [15]. At the same time, SMEs have not enough spare personnel to run specialized departments for supporting processes like knowledge management, quality management or Information Technology (IT) [13, $16,17]$. These very important supporting activities [18] often have to be outsourced or must be carried out by employees in addition to their tasks within the primary activities. Similar to human resources, available financial resources are also a limiting factor for most SMEs. The organizational structure can be characterized as less bureaucratic than larger companies [15]. At the same time, the leadership can often be described as being conservative and more patriarchic. Compared to MNEs the company's strategy is not derived of intensive and methodical accurate analyses and market research but dictated by a strong leader, often the owner of the SME. All these factors do affect the IT strategy of SMEs [17]. Often SMEs do not have an in-house IT department to develop own solutions, at the most, they have a few IT administers to keep the infrastructure running. All other IT related needs like software development are often outsourced $[17,3]$. SMEs tend to buy tailored solutions for particular problems and try to avoid standardized, companywide and expensive solutions (like SAP). One of the reasons in which SMEs opt out of such a commitment is due to substantial financial and time investment in software licenses and training of employees $[19,13]$ as well as dependency on regular updates [17].

Table 1. Advantages and Disadvantages of SMEs compared to larger companies [7, 14, 15, 20]

\begin{tabular}{|l|l|}
\hline Advantage & Disadvantage \\
\hline High flexibility & Less financial resources \\
\hline Less bureaucratic (informal) & $\begin{array}{l}\text { Less human resources (e.g. for supporting } \\
\text { activities) }\end{array}$ \\
\hline Strong ties to customers and suppliers & Often conservative and patriarchic structures \\
\hline Often low fluctuation & Strategy often dictated by strong patriarch \\
\hline Strong focus on customer needs & Dependent on few knowledge carriers \\
\hline $\begin{array}{l}\text { Often inimitable knowledge and experience } \\
\text { in special area (hard to replace) }\end{array}$ & $\begin{array}{l}\text { Often no strong links to external partners for } \\
\text { knowledge transfer (e.g. universities, re- } \\
\text { search institutes) }\end{array}$ \\
\hline & No systematic human resource development \\
\hline
\end{tabular}

In the following paragraphs two practical examples of German manufacturing SMEs with a background in mechanical engineering will be presented. The first company produces a wide variety of products, e.g. gear wheels, for a large and diversified 
customer base with roughly 220 employees most of them blue collars working in manufacturing. The batch size varies from over 1000 to just a single product. A small number of white collars, mostly engineers, are responsible for production planning and control, product development and quality management etc. They have very limited capacity for anything other than direct value adding processes. The company's IT infrastructure has grown over time and was adapted by new IT solutions of external sources whenever new functionalities were needed.

Lately, the customer requirements on product quality and documentation increased, for example some customers requested a complete product resume for the whole production process. Currently, the company is not able to fulfill this request yet, as, first, the existing information system is not prepared for handling such information and second, there is no comprehensive physical tracking and tracing of individual products from raw material to final product in place yet. Concrete actions tackling the challenge are not planned in the near future as the personnel in charge consider the needed resources, both time and money, as too high. At the moment, the SMEs' strong standing in the market with special product knowledge and one-of-a-kind products allows the company to negotiate these customer demands.

The second company, a $1^{\text {st }}$ Tier automotive supplier, is merely ten years old and just recently reached the mark of 100 employees. The company grows significantly over the last years, doubling their production facilities since 2007. Their main products are impellers for turbo chargers for the automotive industry which they produce in large numbers. The company has up-to-date machinery, high level of automation and prides itself with the high quality of their products. The focus on quality leads to a $100 \%$ control of the products at the end of the manufacturing process and additional checks after specific process steps. As the company grows and the output increases, the company experiences that their processes become more complex and are not transparent any more. The company generates a big load of data during the manufacturing process but is as of today not able to fully utilize this potential. The executives slowly acknowledged the problem, especially thinking about the future under the promise of further growth and even higher quality requirements from the customers' side and see the need to improve their information management system. The challenge is, with company and all white collar personnel running at full capacity, to find a way and the time to assess the needs and current condition as well as the future dimensions of the information management system and create an implementation plan.

The experiences of projects with these companies confirmed the observation derived from literature presented at the beginning of the section. In the following sections, an insight on information management in a manufacturing environment is given, also supported by findings of the practical projects with the SMEs.

\section{Information Management in Manufacturing SMEs}

There are numerous benefits that result from implementing a functional information management system. For a manufacturing company being able to do that, it first has to be capable to track and trace individual products, or at least products on batch level throughout their manufacturing processes. This already implies a major challenge for some manufacturing SMEs. At the companies introduced in section two, it is not 
possible to track an individual product over the whole chain and attach measuring data at different steps to it. Interestingly, the second company was at the beginning convinced that they are capable of at least tracking batches throughout their manufacturing process but a closer analysis resulted in various pitfalls changing the original order along the process. One of these pitfalls was just the automated loading of machining robot where always three parts stayed in the cell when the batch was changed.

A general benefit of tracking individual products is that companies can combine relevant product and process information and put it to use later. In the manufacturing of small batches or even single products this offers the advantage of always being able to check what process steps the product already passed and what parameters have been used. This can be the basis for an in-process adjustment of parameters based on the product state before each process step to increase quality in terms of reducing scrap and rework. Other benefits include, for example, proof for demanding customers, efficient product life cycle management and feedback in case of product failure.

When thinking of information management in manufacturing SMEs, one of the major points is that the information processes and the information management infrastructure have to be able to handle the increased information flow and put it to use. Or at least the existing IT infrastructure must offer interfaces to add additional solutions providing the information and interpret it in a valuable way. Engineering specific is the sheer amount and variety of possible information based on process parameters and changes of product state along the production chain. This is crucial as without a capable information infrastructure, the additional amount of information and data can cause more problems than doing well by overwhelming users and systems.

Another aspect to be considered thinking of information management is that manufacturing is a very physical and rough environment. Today, information is often still distributed on paper as screens and computers are considered too fragile by some workers. So it is not only the technical challenge but also a question of rising awareness and creating an open mindedness with the critical stakeholders.

\section{Requirements and Recommendations for Implementation}

Based on the two previous sections, general organizational and operational requirements and recommendations for successful implementation and utilization of a practical information management for manufacturing SMEs will be derived. The focus is on the technical perspective, especially processes and products, to support the SMEs.

In this paper, organizational requirements also include strategic and financial aspects. It is a strategic decision of a company to enforce the implementation of an information management system which involves all hierarchical levels. The management of the SME must not only carefully consider if the company's organizational capability in terms of change management is sufficient but also consider partners and key customers, their demands, interfaces and interdependencies. Furthermore, such a complex project needs qualified personnel with a very specific skill set who can invest the needed time for the project. It is key that there is a commitment from corporate level towards the successful implementation. However, blue collar workers have to be involved as well. Especially in SMEs without highly bureaucratic structures and operation instructions, the blue collar personnel working in manufacturing often have 
their own unique knowledge and experience and finally will be the stakeholders actively using the newly implemented system on a daily basis. If they are not convinced of the benefits of the change, the success of the project is at risk.

The financial aspect cannot be valued high enough. SMEs with a tighter financial basis need to carefully consider the possible costs of the entire project including hardware, software, testing, training, maintenance etc before starting the implementation considering the Total Cost of Ownership (TCO) over the whole life-cycle. A hands on blind start without a realistic estimation of the total costs can lead to chaos and leave the processes in worse conditions than before the implementation effort if the costs get out of hand and the project has to be abandoned half way.

The operational requirements mainly involve technical requirements and requirements concerning the existing information management including IT infrastructure. On the operational level, a basic and very important requirement is to have transparent processes. This requirement is crucial as without knowledge of the own processes, no serious plan can be developed and a successful implementation is off to a bad start. Furthermore, the own products and the information involved to describe these products during the manufacturing process have to be assessed carefully. The product state based view can offer a valuable concept to structure and quantify the information needs on a process and product level [10, 21].

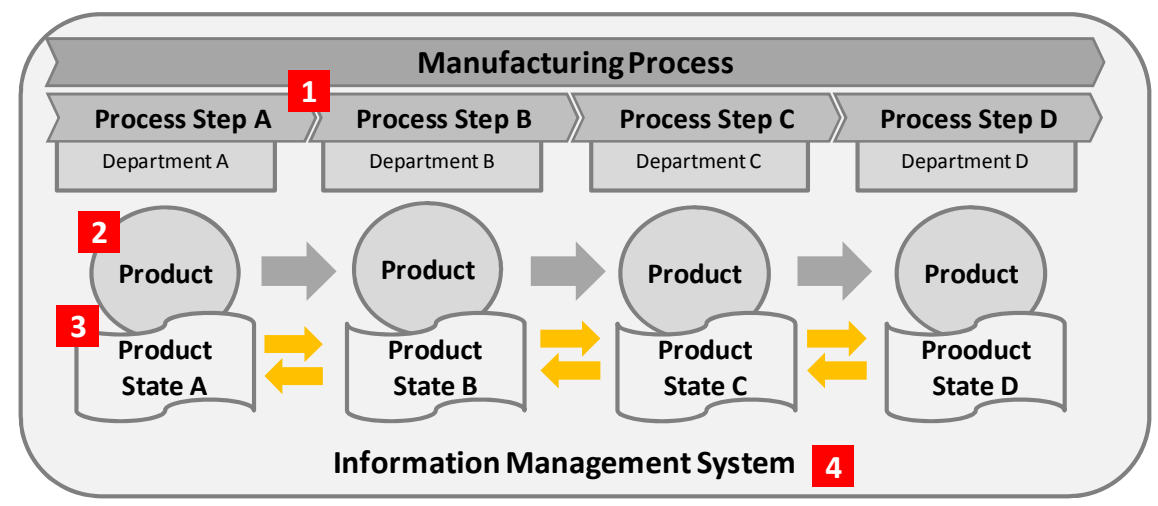

Fig. 2. Main Aspects of the Product State Based View

Fig. 2. provides an overview how the information can be structured through the product state based view. Number one in the figure indicates that the whole manufacturing process has to be considered even so not all process steps take place in one location. In that case it is necessary to think about physical and virtual interfaces between department or company boarders. The physical product (number two) is in the center of the concept. The flow of the physical product is one directional and at each process step value is added to the product and such the product state (number three) changes. The product state compromises all information of the product needed for a successful operation of manufacturing, and thus value adding, processes to reach the desired quality. The product states have descriptive characters and are interdependent 
to each other. The surrounding information management system (number four), integrates the process (number one) and product (number two/three) information, processes the information if needed [21] and distributes it to the right addressee.

Additionally, stakeholders have to be aware of existing capabilities and the available IT infrastructure. It is important to carefully assess and plan the integration of the new system in the available infrastructure. This is challenging for SMEs with their diversified IT solutions and small IT departments as they might need to add additional functionalities to existing systems and at the same time consult different software providers. To assess the dimension of the planed system, the content, the data and information attached to the product at different stages have to be clear. In this case, a consistent application of the product state based view and thus assessment of the relevant information of the product and process in combination with logistics key performance indicators can help to estimate the dimensions realistically. This part is essential, since it is the basis for developing and dimensioning a possible IT solution.

\section{$5 \quad$ Conclusion and Outlook}

This paper gave an insight on the characteristics of manufacturing SMEs. Therefore, an example of two manufacturing SME from the automotive industry were presented. Following the examples, information management in general was elaborated on. Finally, requirements and recommendations for manufacturing SMEs implementing an information management system were offered.

The manufacturing industry is without a doubt a very challenging environment for implementing information management. But there are without doubt numerous benefits of having an integrated information management system for manufacturing SMEs. If a company has a clear vision of its goal and takes the right precautionary measures, the implementation of information management can increase the competitiveness and strengthen the ties to collaboration partners.

But these benefits do not come free of charge. The most significant requirement is transparency of the own processes and products. Also the available IT infrastructure and IT competence within the company have to be considered carefully. The SME has to be able to judge its own capabilities (human, knowledge and finance) unbiased.

In a next step the product state based concept will be developed further. Within this approach, a special focus will be laid on illustration of manufacturing process chain wide interdependencies on the product state characteristic level and derive information needs from customer specifications.

Acknowledgement. This work has been partly funded by the European Commission through ICT Project COIN: Collaboration and Interoperability for networked enterprises (No. ICT-2008-216256). The authors wish to acknowledge the Commission for their support.

\section{References}

1. Thesing, G., Randow, J., Kirchfeld, A., Berberich, S., Webb, A.: New Rules And Old Companies. Bloomberg Businessweek 4198, 72-75 (2010)

2. N.N.: The problem with solid engineering. Economist 8478, 71-73 (2006) 
3. Fink, D., Disterer, G.: International case studies: To what extent is ICT infused into the operations of SMEs? Journal of Enterprise Information Management 6, 608-624 (2006)

4. Schiersch, A.: Inefficiency in the German Mechanical Engineering Sector. DIW Berlin Discussion Paper 949, 1-27 (2009)

5. Seifert, M.: Collaboration Formation in Virtual Organisations by applying prospective Performance Measurement. Dissertation at the University of Bremen, Bremer Schriften zur Integrierten Produkt- und Prozessentwicklung (2009)

6. Sitek, P., Seifert, M., Thoben, K.-D.: Towards inter-organisational perspective for managing quality in virtual organizations. International Journal for Quality and Reliability Management 27(2), 231-246 (2010)

7. Donath, S.: Methode zur Einführung der RFID-Technologie in KMU. In: Ruhland, J., Kirchner, K. (eds.) Jena Research Papers in Business and Economics 10. Interuniversitäres Doktorandenseminar Wirtschaftsinformatik, pp. 49-56 (2009)

8. Wuest, T., Sitek, P., Seifert, M., Thoben, K.-D.: Organisational and technical interdependencies in collaborative production. In: Proceedings of the 17th International Conference on Concurrent Enterprising (ICE 2011), Aachen, Germany, pp. 343-349 (2011)

9. Van Dorp, K.-J.: Tracking and tracing: a structure for development and contemporary practices. Logistics Information Management 15, 24-33 (2002)

10. Wuest, T., Klein, D., Thoben, K.-D.: State of steel product in industrial production processes. Procedia Engineering 10, 2227-2232 (2011)

11. N.N.: Qualitätsmanagementsysteme, Anforderungen. DIN EN ISO 9100 ff:2000 (2000)

12. N.N.: Regulation (EC) No 178/2002 of the European Parliament and of the Council of January 28, 2002 (2002)

13. Ritchie, B., Brindley, C.: CT adoption by SMEs: implications for relationships and management. New Technology, Work and Employment 3, 205-217 (2005)

14. Wagner, K.W., Zacharnik, M.: Qualitätsmanagement für KMU: Qualität sensibilisieren, realisieren, leben. Hanser Verlag, München (2006)

15. Allan, C., Annear, J., Beck, E., Van Beveren, J.: A Framework for the Adoption of ICT and Security Technologies By SME'S. In: 16th Annual Conference of Small Enterprise Association of Australia and New Zealand, pp. 1-10 (2003)

16. Caldeira, M.M., Ward, J.M.: Understanding the successful adaption and use of IS/IT in SMEs: an explanation from Portuguese manufacturing industries. Information Systems Journal 12, 121-152 (2002)

17. Harindranath, G., Dyerson, R., Barnes, D.: ICT Adoption and Use in UK SMEs: a Failure of Initiatives? The Electronic Journal Information Systems Evaluation 2, 91-96 (2008)

18. Porter, M.E.: On Competition. Harvard Business School Publishing, Boston (2008)

19. Wymer, S.A., Reagan, E.A.: Factors influencing e-commerce adaption and use by small and medium businesses. Electronic Markets 4, 438-453 (2005)

20. Forschungsinstitut Betriebliche Bildung (2011), http://www . qualifizieren-imbetrieb.de/wissensmanagement/warum/besonderheiten/

besonderheiten.rsys

21. Irgens, C., Wuest, T., Thoben, K.-D.: Product state based view and machine learning: A suitable approach to increase quality? In: Borangiu, T., Dolgui, A., Dumitrache, I., Pereira, C.E., Vrba, P. (eds.) Information Control for Smarter Manufacturing. Proceedings of the 14th IFAC Symposium on Information Control Problems in Manufacturing, Bucharest, Romania, May 23-25, pp. 190-195 (2012) 